\title{
Earth pressure on cantilever walls at design retained heights
}

\author{
R. A. Day
}

\section{T. Suckling, Cement Foundation, Skanska}

I found this paper very interesting and I am pleased that the relatively straightforward design method described within CIRIA 104 agrees well with the author's finite-element studies. We all knew the CIRIA 104 method worked, as it has been employed successfully since publication in 1984, and now we know that there appears not to be a high degree of conservatism associated with this method.

On this work I have two points. Firstly, I am unclear whether the CIRIA 104 method described by the author is actually the $F_{\mathrm{p}}$ or the $F_{\mathrm{r}}$ method, although I suspect the latter.

Secondly, I found section 5.2 on cantilever wall movement prediction to be slightly misleading, and in need of further clarification. The author states that cantilever walls in high $K_{0}$ soils have a maximum displacement at the top of the wall of $>1 \%$ of the retained height. It is clear to me that this level of predicted movement, if true in reality, is for the long-term condition only when all of the excess pore water pressure induced during construction has had time to reach equilibrium. A long-term cantilever without any positive propping is not a common occurrence within the United Kingdom, where the vast majority of cantilevers are acting in a short-term temporary condition only.

Maximum displacements of short-term cantilevers in high $K_{\mathrm{o}}$ soils are commonly in the order of $0 \cdot 1-0 \cdot 4 \%$ of the retained height, significantly lower than the $1 \%$ value quoted in this paper. There are many published case studies of short-term cantilevers demonstrating this point. ${ }^{1-3}$

In addition, I wonder whether installation effects during the construction of cantilever walls can be considered during the next stage of this research, if there is a next stage, and if these significantly influence the pressures acting on the wall, the bending moments induced and the resulting wall displacements.

\section{Author's response}

The author appreciates the contribution by Mr Suckling. It is pleasing that the results of this study are of interest to the design and construction industry.

The paper compared the finite-element results to those of CIRIA 104. The CIRIA 104 method for design has two quite independent calculations: one to determine the depth of embedment and another for the maximum bending moment. I like to think of these as checks of the geotechnical strength limit state and the structural strength limit state respectively.

The calculation for embedment depth requires the use of a factor of safety. There are many definitions of factor of safety that may be adopted. CIRIA describes five: $F_{\mathrm{r}}, F_{\mathrm{p}}, F_{\mathrm{s}}, F_{\mathrm{np}}$ and $F_{\mathrm{d}}$.

The calculation of maximum bending moment is based on the assumption that the actual maximum bending moment in the real wall is equal to the maximum bending moment in a wall with the same retained height, but with the limiting equilibrium depth of embedment. In this case the value of $F_{\mathrm{r}}, F_{\mathrm{p}}, F_{\mathrm{s}}, F_{\mathrm{np}}$ and $F_{\mathrm{d}}$ are all equal to 1 . The calculation of maximum bending moment is therefore independent of embedment depth and independent of the definition of factor of safety.

The paper is concerned with examining the earth pressure distribution on a wall with the purpose of predicting the bending moment in the case when the factor of safety is greater than 1 . The finite-element results are compared to the CIRIA 104 method of calculating maximum bending moment. As described above, neither $F_{\mathrm{p}}$ nor $F_{\mathrm{r}}$ is used in this calculation.

In Figs 4-7, 14 and 16, the line shown as the CIRIA 104 method is the limiting equilibrium case; $F_{\mathrm{p}}=F_{\mathrm{r}}=1$.

As stated in section 4, the finite-element analyses assume fully drained conditions with zero pore pressure. They are therefore applicable to the long-term condition.

\section{REFERENCES}

1. ST John H. D. et al. Prediction and performance of ground response due to construction of a deep basement at 60 Victoria Embankment. Proceedings of the Wroth Memorial Symposium, Oxford, 1992.

2. FERnie R. and SuCKLING T. P. Simplified approach for estimating lateral wall movement of embedded walls in UK ground. Proceedings of the International Symposium on Geotechnical Aspects of Underground Construction in Soft Ground, London, 1996.

3. LoNG M. Database for retaining wall and ground movements due to deep excavations. Journal of Geotechnical and Geoenvironmental Engineering, ASCE, 2001, Mar. 